14,13

\title{
Структурные превращения при химическом модифицировании поверхности пленки полипиромеллитимида
}

\author{
(С) Д.В. Новиков \\ Санкт-Петербургский государственный лесотехнический университет им. С.М. Кирова, \\ Санкт-Петербург, Россия \\ E-mail: dvnovikov65@mail.ru
}

Поступила в Редакцию 19 марта 2020 г.

В окончательной редакции 19 марта 2020 г.

Принята к публикации 30 марта 2020 г.

По данным электронной микроскопии изучено формирование субмикронного слоя полиамидокислоты (PAAc) на поверхности пленки полипиромеллитимида (PI) при последовательной обработке РI водными растворами щелочи и кислоты. Для анализа топологии распределения кластеров макромолекул РААс на поверхности образцов модифицированной пленки PI применена методика декорирования РААс наночастицами хлорида серебра. Обнаружена упорядоченность пространственного распределения плотности ансамблей декорирующих наночастиц. Показано, что степень порядка немонотонно изменяется с ростом времени щелочного гидролиза РІ. Такое изменение объясняется суперпозицией двух процессов: образования кластеров РААс в результате топохимической реакции в цепях макромолекул РІ и случайной кластеркластерной агрегации. Центрами образования кластеров РААс являются периодически чередующиеся микродомены - плотные агрегаты макромолекул PI. Установлены режимы получения упорядоченной кластерной структуры РААс при модифицировании поверхности РI.

Ключевые слова: полимерные пленки, модифицирование поверхности, кластерная структура, микродомены, электронная микроскопия.

DOI: 10.21883/FTT.2020.08.49621.057

\section{1. Введение}

Процесс создания и накопления новых функциональных групп при полимераналогичных превращениях [1] может быть описан с помощью кластерной перколяционной модели [2]. Согласно этой модели с ростом степени $\beta$ конверсии функциональных групп последовательно происходят следующие процессы: образование конечных кластеров или ансамблей модифицированных макромолекул, кластер-кластерная агрегация и формирование бесконечного кластера, отображающего физическую сетку макромолекул модифицированного полимера. Именно таким образом модифицируется поверхность пленки полипиромеллитимида (PI) [3] в ходе ее последовательной обработки водными растворами щелочи и кислоты $[4,5]$. При этом с ростом параметра $\beta$ в субмикронном поверхностном слое пленки PI образуются и эволюционируют кластеры макромолекул полиамидокислоты (РАAс).

Макромолекулы РААс способны химически взаимодействовать с рядом веществ, например, оксихлоридами и хлоридами переходных металлов [5,6]. Поэтому модифицированные пленки PI могут быть использованы в качестве матриц для получения „сверхрешеток“ наночастиц металлов и их солей. Такие „сверхрешетки“ являются примерами рабочих элементов устройств нанооптики [7], а также твердотельных хемо- и биосенсоров [8].

B работе [5] с применением IR-спектроскопии в варианте MHПВО (ATR) была рассчитана степень $\beta$ конвер- сии имидных групп PI в амидокислотные звенья РААс при вариации времени $\tau$ щелочного гидролиза образцов пленок PI с последующей их обработкой водным раствором кислоты. Было показано, что в мягких условиях гидролиза, в частности, при использовании $2.5 \mathrm{M}$ водного раствора КОН в течение 15 min при 308 K, в поверхностном слое пленки PI образуется соль PAAc. B IR-спектре образцов с ростом $\tau$ уменышается интенсивность полосы $1730 \mathrm{~cm}^{-1}$, отвечающей валентным колебаниям имидных звеньев макромолекул, и увеличивается интенсивность полос, относящихся к амидным группам и карбоксилатаниону. При этом интенсивность полос скелетных колебаний в основной цепи PI остается неизменной. После заключительной обработки пленок водным раствором кислоты в IR-спектре обнаружена полоса $1660 \mathrm{~cm}^{-1}$, отвечающая амидокислотным звеньям [5].

Для анализа кластерной структуры модифицированных пленок PI в работе [5] был использован метод просвечивающей электронной микроскопии (ТЕМ) в варианте декорирования поверхности наночастицами $\mathrm{AgCl}$. Наночастицы создавались при вакуумном термическом напылении хлорида серебра на поверхность образцов. При этом образование частиц происходит в местах локализации кластеров макромолекул РААс, поскольку катионы $\mathrm{Ag}^{+}$формируют донорно-акцепторные комплексы с амидными группами и прочно связываются с карбоксильными группами полимера $[5,8]$.

В работе [5] с использованием модели перколяции на двумерной решетке была описана эволюция кластерной 
структуры полимера при вариации параметра $\beta$, однако не было изучено влияние топологии поверхности пленки PI на перколяционный переход PI $\rightarrow$ PAАс. Отметим, что этот переход происходит в результате топохимической реакции и, согласно спектральным данным, кинетическая зависимость отношения интенсивностей полос $1660 \mathrm{~cm}^{-1}$ и $1730 \mathrm{~cm}^{-1}$ от параметра $\tau$ имеет характерный S-образный вид [5].

Ранее на основе данных TEM и малоуглового рентгеновского рассеяния (SAXS) для пленки PI была предложена микродоменная структурная модель [9], в которой узлами структурного каркаса полимера являются микродомены или агрегаты плотноупакованных макромолекул. Микронеоднородная структура PI должна влиять на процессы образования, ориентации и упорядочения кластеров РААс при химическом модифицировании поверхности полимера.

С целью обнаружения возможного влияния надмолекулярной структуры полимера на превращение $\mathrm{PI} \rightarrow$ PAАс в настоящей работе по данным TEM $[5,7]$ изучены текстура поверхности и пространственные корреляции типа „Плотность-плотность“ для исходной пленки и модифицированных образцов.

\section{2. Объекты и методы исследования}

В работе использовалась промышленная неориентированная пленка PI толщиной $\sim 40 \mu \mathrm{m}$, полученная на основе пиромеллитового ангидрида и пара-диаминодифенилового эфира. Щелочной гидролиз образцов осуществлялся $2.5 \mathrm{M}$ водным раствором КОН при $308 \mathrm{~K}$ в интервале времени $\tau=2-10 \mathrm{~min}$, затем образцы промывались бидистиллятом и обрабатывались $2.5 \mathrm{M}$ водным раствором $\mathrm{H}_{2} \mathrm{SO}_{4}$ в течение 2 min при $298 \mathrm{~K}$. Полученные модифицированные пленки промывались и сушились на воздухе.

Для ТЕМ-анализа топологической структуры поверхности исходной пленки РI использовалась методика декорирования золотом „химических меток“ хемосорбированного брома. Данная методика, применимая к аморфным и мезоморфным полиимидам $[10,11]$, позволяет визуализировать топологию распределения флуктуаций плотности на исследуемой поверхности в субмикронном и микронном диапазонах масштаба. Препарирование образцов для ТЕМ осуществлялось путем предварительной активации поверхности пленок молекулярным бромом по методике [10] с последующим вакуумным термическим напылением золота. Наночастицы золота отделялись от поверхности с помощью опорной угольной реплики и изучались в просвечивающем электронном микроскопе EMV100L. Использовались координаты не менее 5000 частиц, определенные при компьютерной оцифровке их положений в двумерном изображении декорированной поверхности площадью $2-2.5 \mu \mathrm{m}^{2}$.
Декорирование поверхности модифицированных пленок осуществлялось путем вакуумного термического напыления $\mathrm{AgCl}$ [5].

Изучение пространственных корреляций типа плотность-плотность на поверхности образцов и определение корреляционной длины $\xi$ проводились с помощью так называемых „крупнозернистых“ радиальных функций $g(R)$ распределения декорирующих наночастиц. Для получения функций $g(R)$ использовалось пошаговое сканирование плотности распределения частиц на двумерных изображениях поверхности с шагом, соответствующим наиболее вероятному расстоянию $r$ между частицами [11]. Величина $r$ составляет $\sim 30 \mathrm{~nm}$ для наночастиц золота и $\sim 18 \mathrm{~nm}$ для наночастиц хлорида серебра.

Индикатрисы плотности $\rho$ распределения частиц рассчитывались при усреднении по прямоугольникам $2 r \times \xi$ с центром в частицах и изменении угла $\theta$ ориентации прямоугольников [11]. Осцилляции плотности по направлениям осей текстуры образцов изучались с помощью соответствующих функций $g(R)$.

При компьютерной обработке изображений декорирующие наночастицы объединялись в ансамбли или кластеры по принципу перекрывания „координационных сфер“ частиц [12].

\section{3. Результаты и их обсуждение}

Декорирующие наночастицы золота на поверхности пленки PI (рис. 1) имеют довольно широкое распределение по размеру $(6-80 \mathrm{~nm})$. Скопления мелких наночастиц $(6-15 \mathrm{~nm})$ отображают флуктуации повышенной плотности упаковки макромолекул. Сравнительно

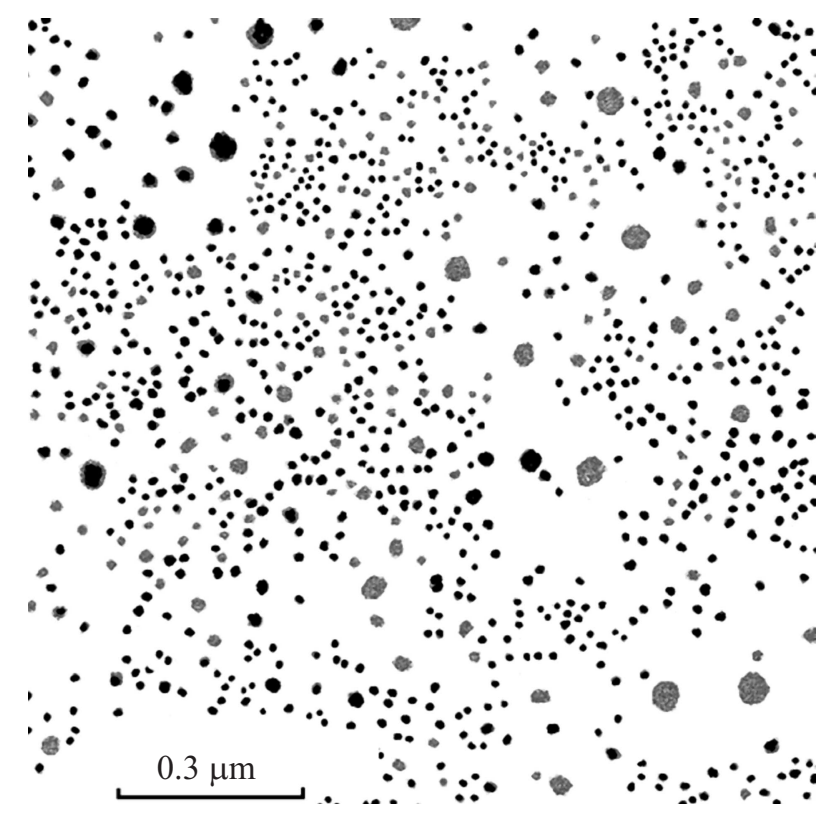

Рис. 1. Электронная микрофотография декорированной золотом поверхности пленки PI. 

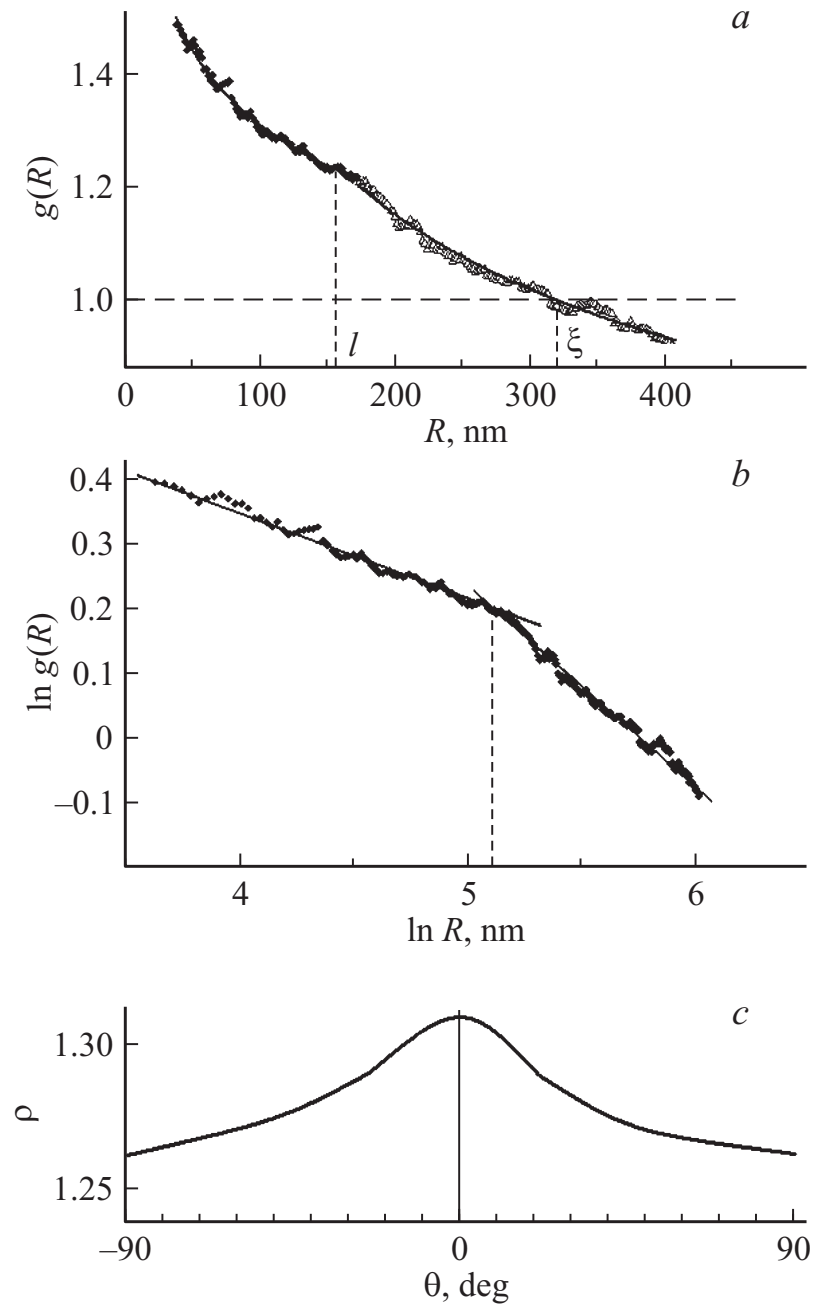

Рис. 2. „Крупнозернистая“радиальная функция $g(R)$ распределения наночастиц золота на декорированной поверхности пленки PI в обычных $(a)$ и двойных логарифмических координатах $(b)$. Функция $g(R)$ построена при сканировании плотности распределения наночастиц с шагом $50 \mathrm{~nm}$. Индикатриса относительной (по отношению к средней по поверхности) плотности $\rho$ распределения наночастиц золота $(c)$. Ось ординат $(\theta=0$ градусов $)$ соответствует оси текстуры.

небольшое число крупных частиц золота $(40-80 \mathrm{~nm})$ соответствует менее плотным областям поверхности [11].

Локальная плотность распределения декорирующих наночастиц флуктуирует, а функция $g(R)$ радиального распределения флуктуаций плотности (рис. 2,a) спадает с ростом масштаба $R$ по степенному закону $g(R) \propto R^{D-2}$, характерному для фрактальных объектов с фрактальной размерностью $D$ [2]. При этом по шкале масштаба выявляются два участка, отвечающие значениям $D 1.9$ и $1.7 \pm 0.02$. Эти масштабные области четко обнаруживаются при построении функции $g(R)$ в двойных логарифмических координатах (рис. 2, $b$ ). Полученный результат удовлетворяет микродоменной структурной модели PI: начальный участок $(R<150 \mathrm{~nm})$ функции $g(R)$ соответствует микродоменам максимального размера $l \sim 150 \mathrm{~nm}$ и фрактальной размерности $D \sim 1.9$ (рис. 2, $a)$, второй участок $(R>150 \mathrm{~nm})$ отображает самоподобную $(D \sim 1.7)$ физическую сетку макромолекул (бесконечный кластер), узлами которой являются связанные проходными цепями микродомены. Корреляционная длина $\xi$ бесконечного кластера составляет $\sim 320 \mathrm{~nm}$ (рис. 2,a), а занимаемая им доля двумерного пространства [11] близка к 0.6.

На рис. 2, $c$ представлена индикатриса относительной плотности $\rho$ распределения наночастиц золота на поверхности пленки PI. Полученная угловая зависимость $\rho(\theta)$ соответствует аксиальной текстуре поверхности, при этом плотности вдоль и поперек оси текстуры отличаются не более чем на $5 \%$. Анизотропия плотности объясняется возникновением слабого ориентационного упорядочения фрагментов макромолекул в поверхностном слое ароматических полиимидов [11]. Поперек оси текстуры наблюдается периодичность распределения плотности с периодом $\sim 350 \mathrm{~nm}$ (рис. 3, кривая 2), а вдоль оси периодичность отсутствует (рис. 3, кривая 1). Функция $g(R)$, построенная вдоль оси текстуры, имеет точку перегиба вблизи $R \sim 150 \mathrm{~nm}$, что соответствует максимальному размеру микродоменов и указывает на их преимущественную одноосную ориентацию.

Для получения информации о топологии пространственного распределения микродоменов использовалась процедура группировки декорирующих наночастиц, формирующих наиболее плотные скопления. Такие частицы выбирались из общего ансамбля по результатам измерения межчастичных расстояний [12]. При этом группировались частицы, центры которых удалены от ближайших соседей на расстояние, не превышающее некоторое заданное значение $d$. С ростом $d$ увеличиваются среднее число частиц в группах и степень заполнения ими поверхности, а пространственные корреляции между группами ослабевают (рис. 4). При вариации значения $d$

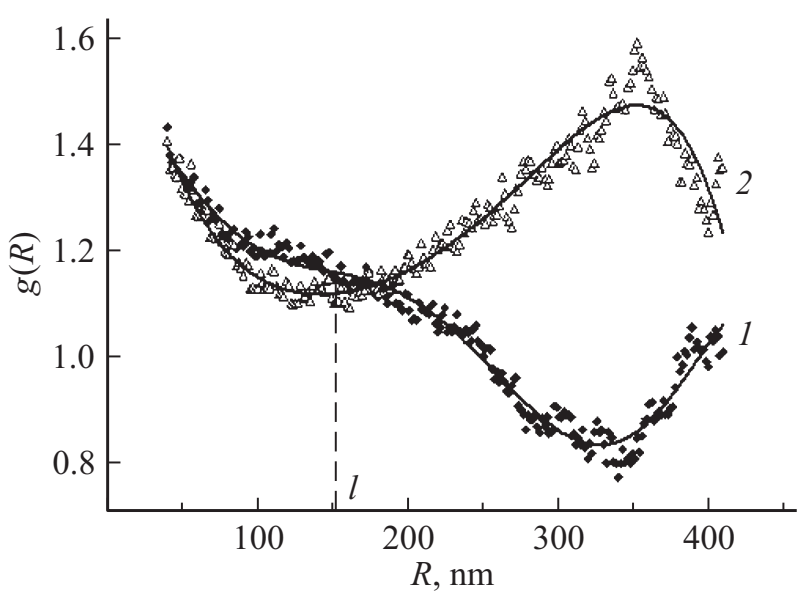

Рис. 3. „Крупнозернистые“радиальные функции $g(R)$ распределения декорирующих наночастиц золота на поверхности пленки PI. Функции построены вдоль (кривая 1) и поперек (кривая 2) оси текстуры. 
выявляются такие группы частиц (рис. 4 , кривые 1 и 2 ), распределение которых по поверхности является периодическим с периодом $L \sim 120 \mathrm{~nm}$. Следует полагать, что эти группы частиц или конечные кластеры отображают периодически чередующиеся микродомены. Средняя по поверхности концентрация $C$ кластеров составляет $\sim 1.5 \cdot 10^{-4} \mathrm{~nm}^{2}$, а их средний радиус, рассчитанный по соотношению: $\langle R\rangle \sim 1 /(2 C L)$ [9], близок к $30 \mathrm{~nm}$ и соответствует гирорадиусу микродоменов согласно данным SAXS [9]. Отметим, что плотные надмолекулярные образования визуально обнаруживаются на микрофотографии ТЕМ угольной реплики с поверхности пленки PI, обработанной в плазме высокочастотного кислородного разряда [9], однако низкий контраст изображения затрудняет его компьютерную обработку.

Известно [13,14], что микродоменная структура полимера вносит определенную специфику в кинетику полимераналогичных превращений. Например [15], в пленке триацетата целлюлозы (СТА) щелочной гидролиз полимера начинается в локальных областях - микродоменах [16], в которых реализуется упорядоченность макромолекул нематического типа. Этот факт объясняется тем, что в микродоменах СТА пространственная
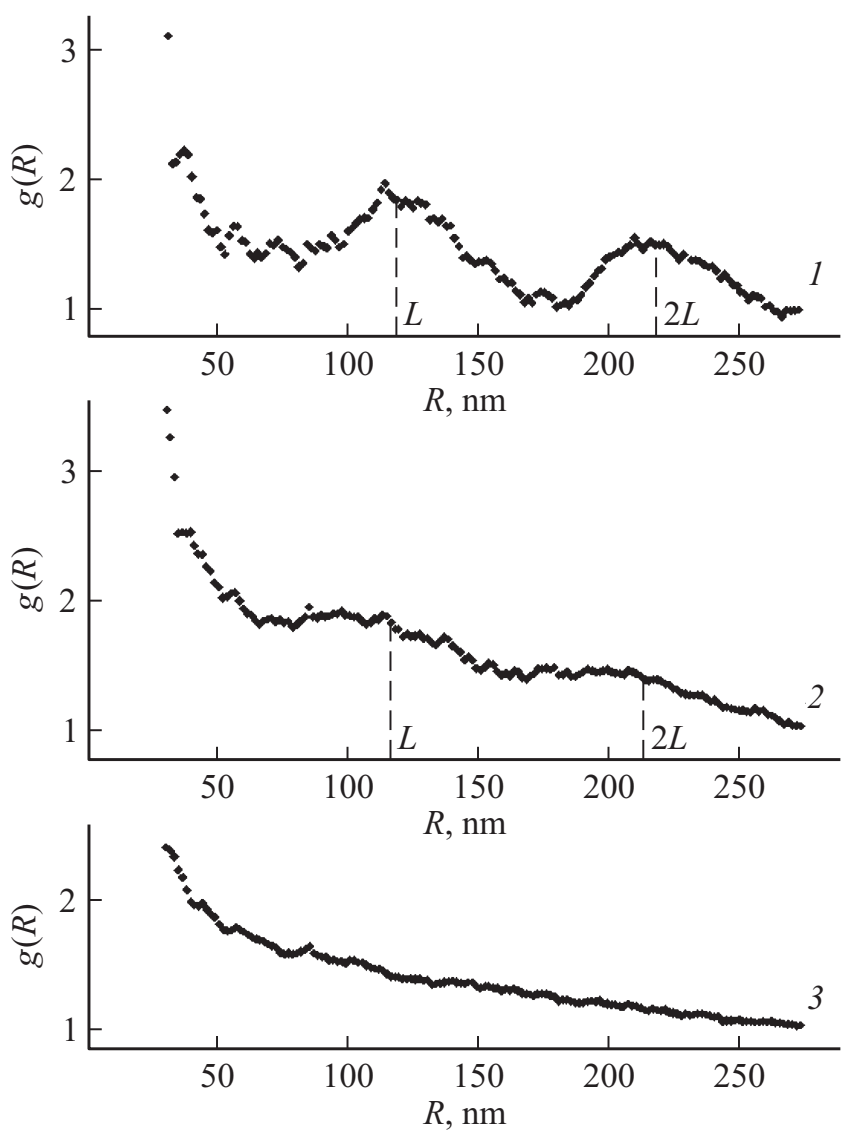

Рис. 4. „Крупнозернистые“ радиальные функции $g(R)$ распределения наночастиц золота на декорированной поверхности пленки PI. Наночастицы отобраны из общего ансамбля при $d=17$ (кривая 1), 19 (кривая 2) и $21 \mathrm{~nm}$ (кривая 3). Функции $g(R)$ построены с шагом $30 \mathrm{~nm}$. Пояснения в тексте.
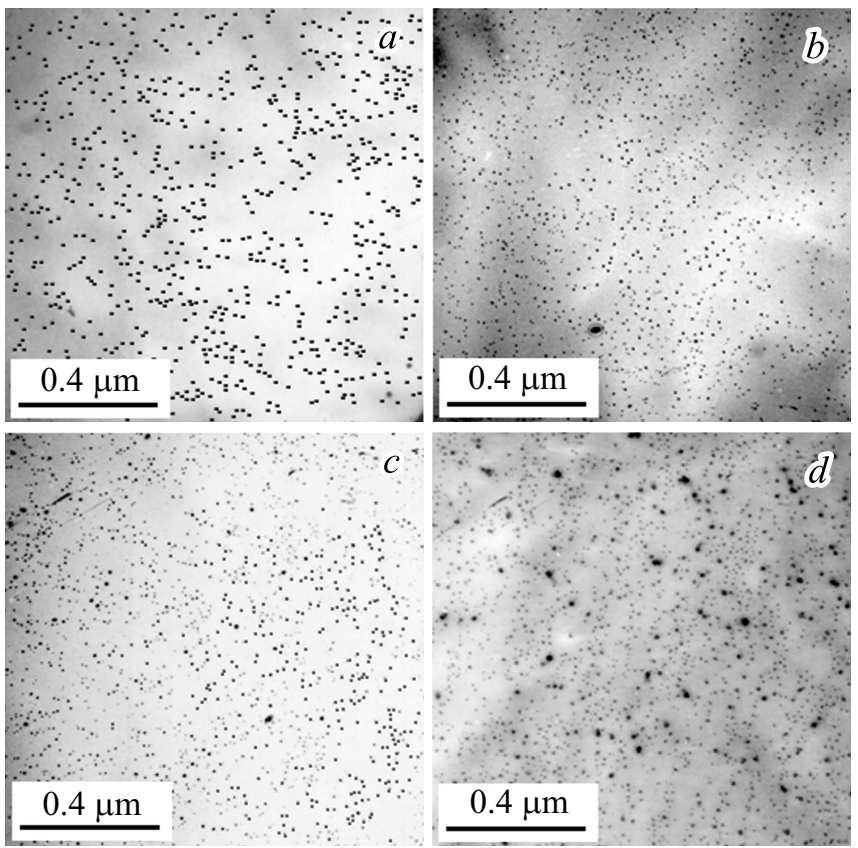

Рис. 5. Электронные микрофотографии наночастиц $\mathrm{AgCl}$ на декорированной поверхности пленок РI, модифицированных в течение $\tau=2(a), 6(b), 8(c)$ и $10 \mathrm{~min}(d)$.

ориентация сложноэфирных групп макромолекул облегчает реакцию гидролиза и последующего формирования внутримолекулярных водородных связей [15].

В пленке PI щелочной гидролиз полимера происходит подобно СТА. Пространственное распределение декорирующих наночастиц $\mathrm{AgCl}$ на поверхности модифицированных пленок PI неоднородно - имеются области с повышенной локальной плотностью частиц (рис. 5). Эти участки поверхности образцов соответствуют кластерам макромолекул РААс. С увеличением времени $\tau$ щелочного гидролиза PI или степени $\beta$ конверсии PI $\rightarrow$ PAAc плотность распределения частиц возрастает, а концентрация кластеров РААс проходит через максимум [5]. Такие изменения согласуются с теорией перколяции.

Плотность распределения ансамблей наночастиц, маркирующих кластеры РААс, с ростом масштаба $R$ флуктуирует периодически (рис. 6). Период $L$ чередования конечных кластеров составляет $80-120 \mathrm{~nm}$ и возрастает по мере превращения PI $\rightarrow$ PAАс. Бесконечный кластер макромолекул РАAс, формирующийся при $\tau=10 \mathrm{~min}$ ( $\beta=68 \%)$, имеет периодическую структуру с периодом $120 \mathrm{~nm}$, как и чередование микродоменов в исходной пленке РІ. При увеличении степени заполнения поверхности пленок PI кластерами PAAc пространственные корреляции ,Плотность-плотность“ изменяются немонотонно: с ростом параметра $\beta$ в интервале $\beta=20-60 \%$ $(\tau=2-8 \mathrm{~min})$ степень порядка (интенсивность максимумов функции $g(R))$ уменьшается, а при формировании физической сетки макромолекул РААс при $\beta=68 \%$ $(\tau=10 \mathrm{~min})$ скачком возрастает. 

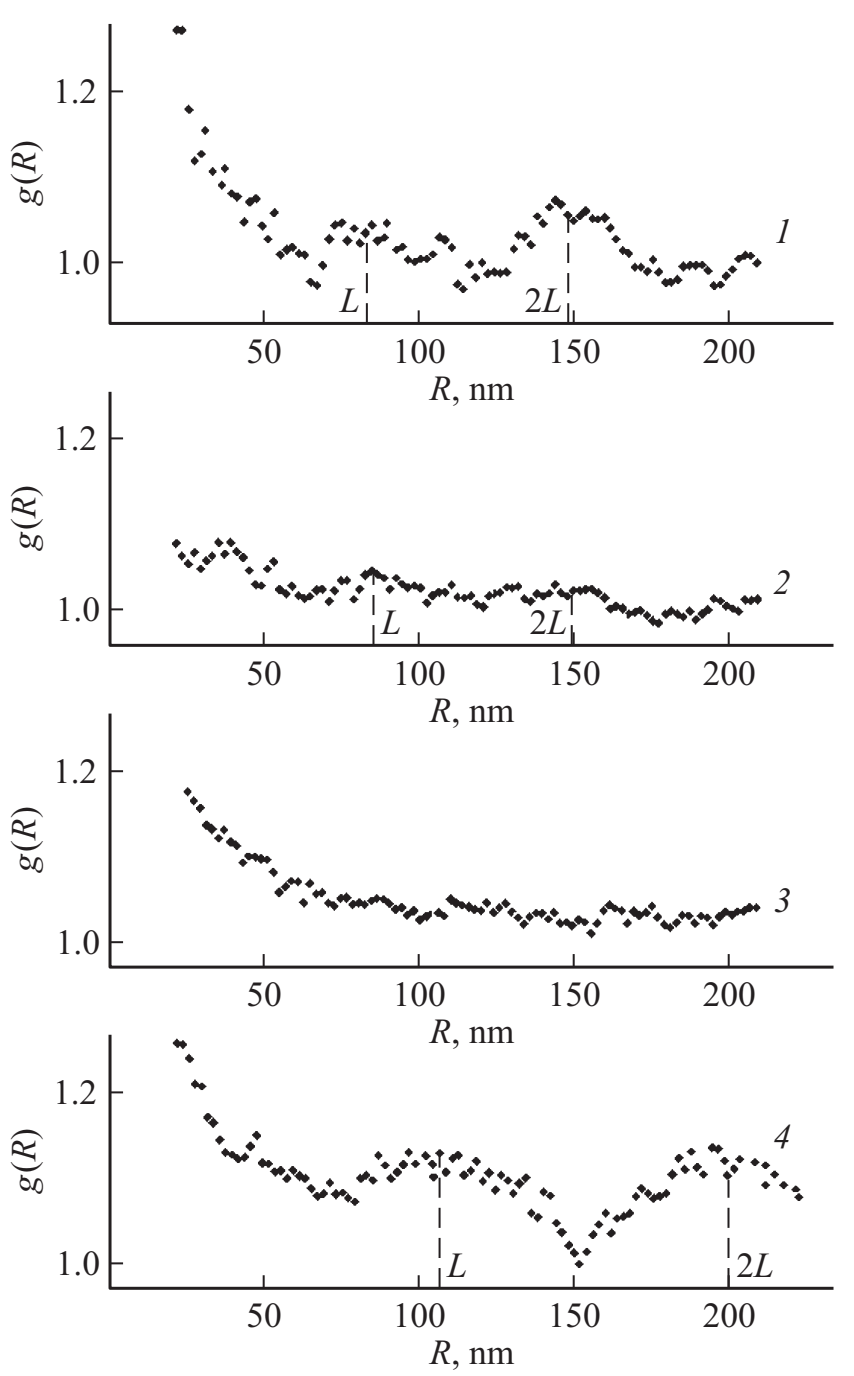

Рис. 6. Радиальные функции $g(R)$ распределения ансамблей (кластеров) наночастиц $\mathrm{AgCl}$ на поверхности пленок PI, модифицированных в течение $\tau=2$ (кривая 1), 6 (кривая 2), 8 (кривая 3) и 10 (кривая 4 ) min. Функции $g(R)$ построены при сканировании плотности распределения наночастиц с шагом $20 \mathrm{~nm}$.

Периодичность кластеров макромолекул РААс объясняется их преимущественным образованием в местах локализации регулярно чередующихся микродоменов PI. На начальной стадии щелочного гидролиза PI, например при $\tau=2 \min$ [5], средняя концентрация кластеров РААс по порядку величины соответствует концентрации $C$ микродоменов. В интервале $\beta<\beta_{c}$, где $\beta_{c}-$ критическая степень конверсии при формировании бесконечного кластера макромолекул РААс, характер изменения пространственных корреляций ,Плотность-плотность“ обусловлен влиянием случайной кластер-кластерной агрегации на процесс кластерообразования. При $\tau=8 \mathrm{~min}$ $(\beta=58 \%)$ вблизи $\beta_{c}$ наблюдается степенное распределение кластеров по размеру (числу частиц $s$ ): доля $n_{s}$ кластеров, содержащих $\mathrm{s}$ частиц, выражается как $n_{s} \propto s^{-x}$ (рис. 7), причем $x=2 \pm 0.05$ в полном соответствии со статистической теорией протекания [2].

$\mathrm{C}$ ростом степени $\beta$ конверсии $\mathrm{PI} \rightarrow$ PAАс происходит немонотонное изменение текстуры поверхности модифицированных пленок (рис. 8). В образце, отвечающем

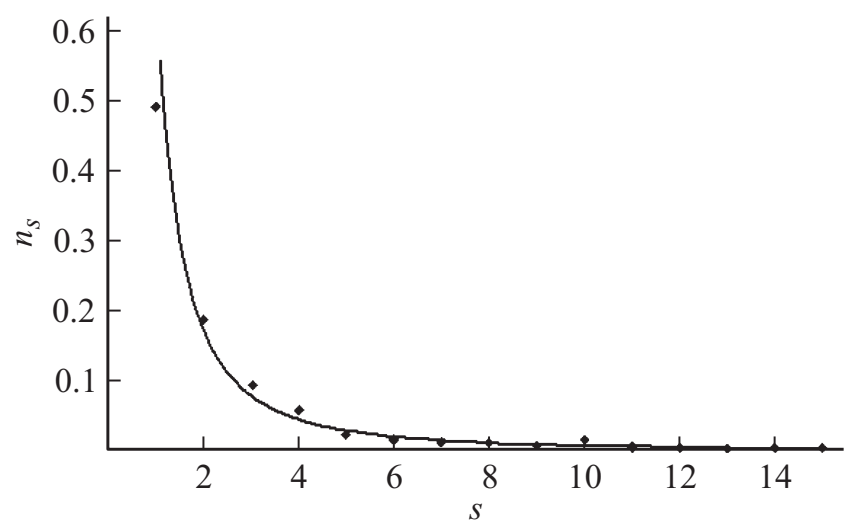

Рис. 7. Кривая распределения ансамблей (кластеров) наночастиц $\mathrm{AgCl}$ по размеру (числу частиц $s$ ) на поверхности пленки PI, модифицированной в течение $\tau=8 \mathrm{~min}$. Кривая описывается степенной функцией $n_{s} \propto s^{-2 \pm 0.05}$.
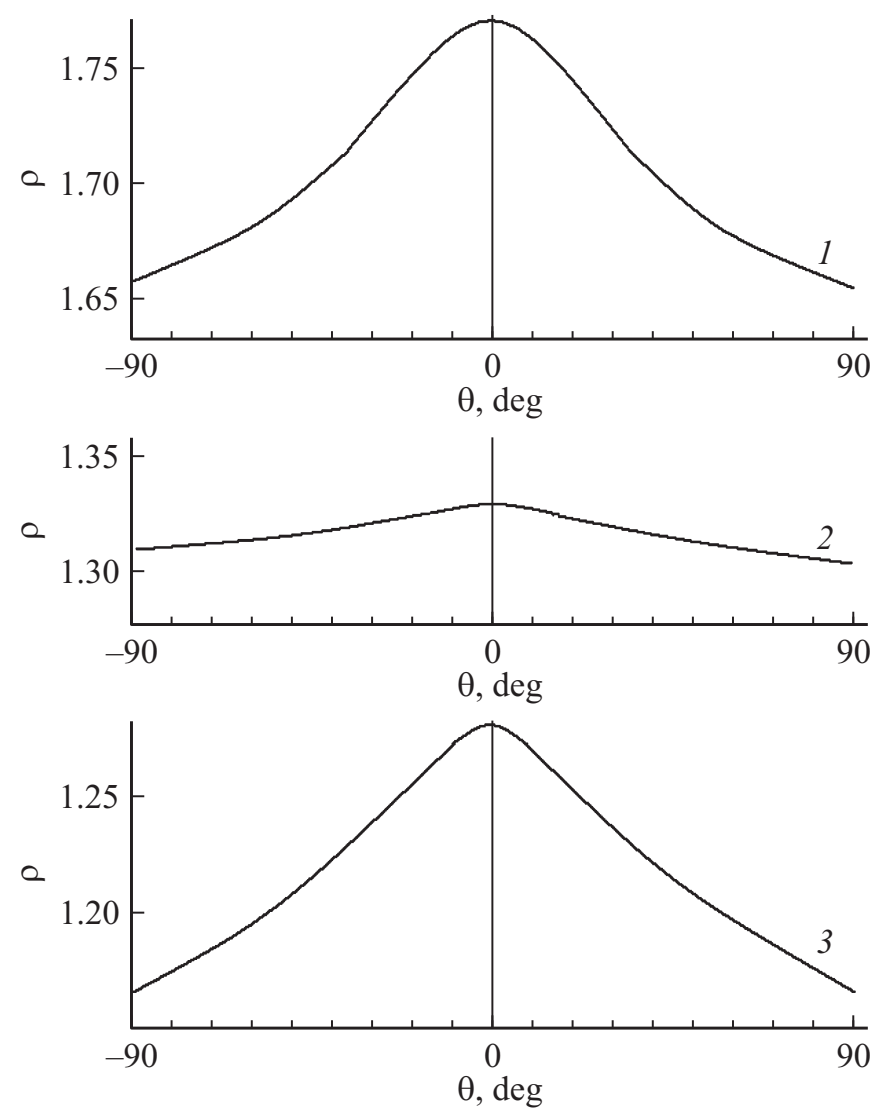

Рис. 8. Индикатрисы относительной плотности $\rho$ распределения наночастиц $\mathrm{AgCl}$ на поверхности пленок PI, модифицированных в течение $\tau=2$ (кривая 1), 8 (кривая 2) и 10 (кривая 3$) \mathrm{min}$. Ось ординат $(\theta=0$ градусов) соответствует оси текстуры. 
$\tau=2 \mathrm{~min}$, наблюдается анизотропия плотности и, как следствие, аксиальная текстура поверхности. Отличие в плотностях вдоль и поперек оси текстуры составляет около 7\% (рис. 8 , кривая 1). Можно заключить, что на начальной стадии модифицирования пленок PI конечные кластеры РААс ориентированы по направлению текстуры поверхности немодифицированного образца. В ходе кластер-кластерной агрегации происходит образование разветвленных кластеров РААс, и за время полупревращения $\tau=8 \mathrm{~min}$ (рис. 8, кривая 2) ориентационный порядок пропадает, а одноосная текстура поверхности сглаживается. При образовании непрерывной физической сетки макромолекул РААс происходит восстановление одноосной текстуры (рис. 8 , кривая 3 ).

\section{4. Заключение}

Превращение PI $\rightarrow$ PAAс в поверхностном слое полимерной пленки представляет собой перколяционный переход, проходящий по кластерному механизму под влиянием анизотропной микродоменной структуры PI. Центрами образования кластеров PAAc в пленке PI являются микродомены - агрегаты плотноупакованных цепей макромолекул. Возникающие кластеры РААс упорядочены вследствие исходного периодического чередования микродоменов.

Топология пространственного распределения кластеров РААс может быть изучена методом ТЕМ в варианте декорирования поверхности пленки наночастицами хлорида серебра.

Исследование пространственных корреляций между ансамблями декорирующих наночастиц $\mathrm{AgCl}$ позволило выделить три стадии перколяционного перехода в зависимости от степени $\beta$ конверсии $\mathrm{PI} \rightarrow \mathrm{PAAc}$. Начальная стадия $(\beta \sim 20 \%)$ связана с образованием пространственно упорядоченных, одноосно ориентированных конечных кластеров РААс. Последующая стадия $(\beta \sim 30-60 \%)$ выражается в формировании разветвленных кластеров за счет кластер-кластерной агрегации. При этом ослабевают пространственные корреляции типа „плотность-плотность“ и резко уменьшается степень ориентационного порядка. На финальной стадии конверсии $(\beta \sim 68 \%)$ возникает бесконечный кластер или непрерывная периодическая физическая сетка макромолекул РААс.

Пленка PI представляет собой уникальную квазирешетку частиц - микродоменов, что позволяет использовать химическое модифицирование поверхности полимера для создания регулярных кластерных субмикронных структур. Например, превращение PI $\rightarrow$ PAAc при $\beta \sim 20 \%$ происходит фактически по матричному репликационному механизму, в результате которого выявляются упорядоченные микродомены - места формирования дискретных кластеров РААс со средним размером $\sim 50 \mathrm{~nm}$.

\section{Конфрликт интересов}

Автор заявляет, что у него нет конфликта интересов.

\section{Список литературы}

[1] В.Н. Кулезнев, В.А. Шершнев. Химия и физика полимеров. Колос, М. (2007). 367 c.

[2] Е. Федер. Фракталы. Мир, М. (1991). 254 с. [J. Feder. Fractals. Plenum Press, N. Y., London (1988). 260 p.].

[3] М.И. Бессонов, М.М. Котон, В.В. Кудрявцев, Л.А. Лайус. Полиимиды - класс термостойких полимеров. Наука, Л. (1983). $328 \mathrm{c}$.

[4] A.N. Krasowsky, V.G. Baranov, E.S. Edilyan, L.G. Shaltyko. Plastics Rubber Proc. Appl. 12, 183 (1989).

[5] Д.В. Новиков, А.Н. Красовский. Коллоидн. журн. 65, 62 (2003).

[6] О.В. Рева, Т.П. Воробьева. ЖПХ 71, 498 (1997).

[7] А.Н. Красовский, Д.В. Новиков. ЖПХ 72, 1518 (1999).

[8] И.П. Суздалев. Нанотехнология: физико-химия нанокластеров, наноструктур и наноматериалов. КомКнига, (2006). $592 \mathrm{c}$.

[9] Д.В. Новиков, Т.Е. Суханова, В.К. Лаврентьев, М.Э. Вылегжанина. Высокомолекулярн. соединения 41А, 1266 (1999).

[10] Д.В. Новиков, Т.Е. Суханова, В.М. Светличный, И.В. Гофман, А.И. Григорьев, А.Л. Диденко, Т.А. Маричева, В.В. Кудрявцев. Высокомолекулярн. соединения 43А, 655 (2001).

[11] Д.В. Новиков, В.М. Светличный, А.А. Мартыненков. ФТТ 61, 1391 (2019).

[12] Д.В. Новиков, А.Н. Красовский, В.Н. Филиппов. ФТТ 56, 2246 (2014).

[13] Ю.П. Ямпольский. Успехи химии 76, 66 (2007).

[14] А.В. Чертович, Д.В. Гусева, Е.Н. Говорун, Я.В. Кудрявцев, А.Д. Литманович. Высокомолекулярн. соединения 51А, 1516 (2009).

[15] Р.Г. Жбанков, Н.В. Иванова, Е.В. Королик. Химия древесины 5, 16 (1977).

[16] Д.В. Новиков, А.Н. Красовский, С.С. Мнацаканов. ФТТ 54, 382 (2012).

Редактор К.В. Емцев 